\title{
Arakawa's Reaction of One Lactant Observed during One Year.
}

56th Report of the Peroxidase Reaction.

\author{
By \\ Yoshitaka Uga. \\ (宇贺 義 孝) \\ (From the Department of Pediatrics, Faculty of Medi- \\ cine, Tohoku Imperial University, Sendai. \\ Director: Prof. A. Sato.)
}

It is a tedious work to follow A rak a wa's reaction each day during the whole length of the admission of a breast-fed infant. It is a still far more difficult task to do the same during a whole year in the case of a healthy baby. I desire to report here a clinical experience as well as a clinical experiment concerning the Arakawa reaction observed during one whole year on a healthy lactant with a normal baby.

\section{Method of Ixvestigation.}

1. Mother's milk was collected at 8 o'clock A. M. every day, and always before feeding. The amount collected each time was more than 5 c.c. from each breast. Though the amount necessary for testing Arakawa's reaction is 1 c.c., it is always desirable to collect a much larger amount than 1 c.c., to obtain a reliable result, but collecting more than 5 c.c. every day during the whole year was a difficult task of course.

2. Arakawa's reaction of the milk samples were done within three hours of obtaining, and the reaction itself was followed as late as 5 minutes. And the time of the first appearance of $(++)$ was marked with a sign for comparison (Cf. Thick types in Tables).

3. State of mother and baby at birth. The lactant was 23 years of age, a healthy primipara with only a slight nausea gravidarum in her pregnancy. The term expected was May 22nd 1933, but the actual 
birth took place on May 25th. No accident in puerperium. Both breasts of an almost equal size; nips not abnormal, abundant secretion. Child, 2900 grms. at birth, severing of umbilical cord on the fifth day after birth. One week after birth, slight jaundice of a short duration.

\section{Restit of Investigation.}

1. Arakawa's Reaction Observed during One Year.

We have known from our daily clinical experience that in most cases Arakawa's reaction of one lactant is not absolutely constant every day, but we have never before investigated the reaction so long as one year.

It is important in the first place to mention that human milk should be strongly positive to A rakawa's reaction and remain so in an ideal case, because Araka wa-positive human milk is a good milk as has been shown in a number of papers ${ }^{1-8}$ from our Laboratory: The following is an example of constant and good Arakawa's reaction (Cf. Table I). But a succession of such ideal reactions or an absolutely constant and good reaction is rather an exceptional case. In most cases, mammary glands secrete human milk more

\section{TABLE I.}

Constant and strong Arakawa's reaction (of mother of an infant of 11 months).

\begin{tabular}{|c|c|c|c|c|c|c|c|}
\hline \multirow{3}{*}{ fat } & \multicolumn{7}{|c|}{ Arakawa's reaction } \\
\hline & \multicolumn{3}{|c|}{ Right } & \multicolumn{4}{|c|}{ Left } \\
\hline & $0^{\prime} \quad 1^{\prime}$ & $2^{\prime} 3^{\prime}$ & $4^{\prime} 5^{\prime}$ & $0^{\prime} \quad 1^{\prime}$ & $2^{\prime} \quad 3^{\prime}$ & $4^{\prime}$ & $5^{\prime}$ \\
\hline VII & $+\rightarrow(t)$ & $(\mathrm{H})(\mathrm{H})($ & $(\mathrm{H})(\mathrm{Ht})$ & $(H)(H)$ & $(\mathrm{Ht})(\mathrm{Ht})$ & (H) & (\#) \\
\hline & (H) & $(t+)(t+)$ & $(t+)(t+)$ & $(H)(H)$ & $(H+(H+)$ & (H) & (H) \\
\hline 25. , & it) & $(t+)(t+)$ & (H) $(\mathrm{HH})$ & $(H)(H)$ & $(H+1)(H)$ & (世) & (tit) \\
\hline & $(H)$ & $(+t)(H+)$ & $(H)(H)$ & $(-)(t+)$ & $(H)(H+)$ & $(\mathrm{Ht})$ & $(H$ \\
\hline & (H) & (H) $(\mathrm{H}+)$ & $(H+H)(H+)$ & $(H)(H+)$ & $(H)(H+)$ & $(+H)$ & $(t$ \\
\hline & $(+)(H)$ & $(\mathrm{HH})(\mathrm{H})$ & (H) $(\mathrm{H+})$ & $(+)($ (H) & $(H+)(H)$ & (tH) & $(H$ \\
\hline & $(+)(H)$ & (H) $(\mathrm{H}+\mathrm{H})$ & (H) (Hitt) & $(H)(H)$ & $\left(\mathrm{H}+\mathrm{H}^{\prime}\right)(\mathrm{H})$ & (姍) & (it \\
\hline & $(+$ & $(t+t)(+H)$ & (Ht) $(4 t)$ & $(H)(t+t)$ & $(\mathrm{HH})(\mathrm{Ht})$ & $(+4)$ & (H+t) \\
\hline & $(+)(+)$ & $(H)(H)$ & $(t+t)(t+f)$ & $(H)\left(H^{1}\right)$ & $(H+)(H)$ & (䩜) & $(+t)$ \\
\hline 1. VIII & $(+$ & (H) $(H+1)$ & $(\mathrm{Ht})(\mathrm{Ht})$ & $(H)(H+H)$ & $(+\mathrm{Ht})(\mathrm{H})$ & (H) & 4) \\
\hline$"$ & $(+)(H)$ & (H) $(+H)$ & $(t+t)(t+t)$ & $(t+1)(t h$ & (A) $($ (\#) & $(+4)$ & (At) \\
\hline 3. & + & th & th & $t+t$ & $n+$ & (tt) & \\
\hline
\end{tabular}

1) A. S ato, Jikken Tho, 1932, 18, 1292.

2) A. Sato, Jikken Iho, 1933, 19, 1554 .

3) M. Chiba, Tohoku J. Exp. Med., 1932, 19, 486.

4) T. Suzuki, Tohokn J. Exp, Med., 1934, 23, 23.

5) J. Nozaki, Tohoku J. Exp. Med., 1934, 23, 60.

6) A. Taka matsu and A. Sato, Tohoku J. Exp. Ned., 1934, 23, 506.

7) K. As a kura, Tohoku J. Exp. Med, 1932, $19,275$.

8) J. Kim ura, Tohoku J. Exp. Med., 1934, 23, 494. 
TABLE II.

Arakawa's Reaction of Human Milk of a Lactant during One Whote Year.

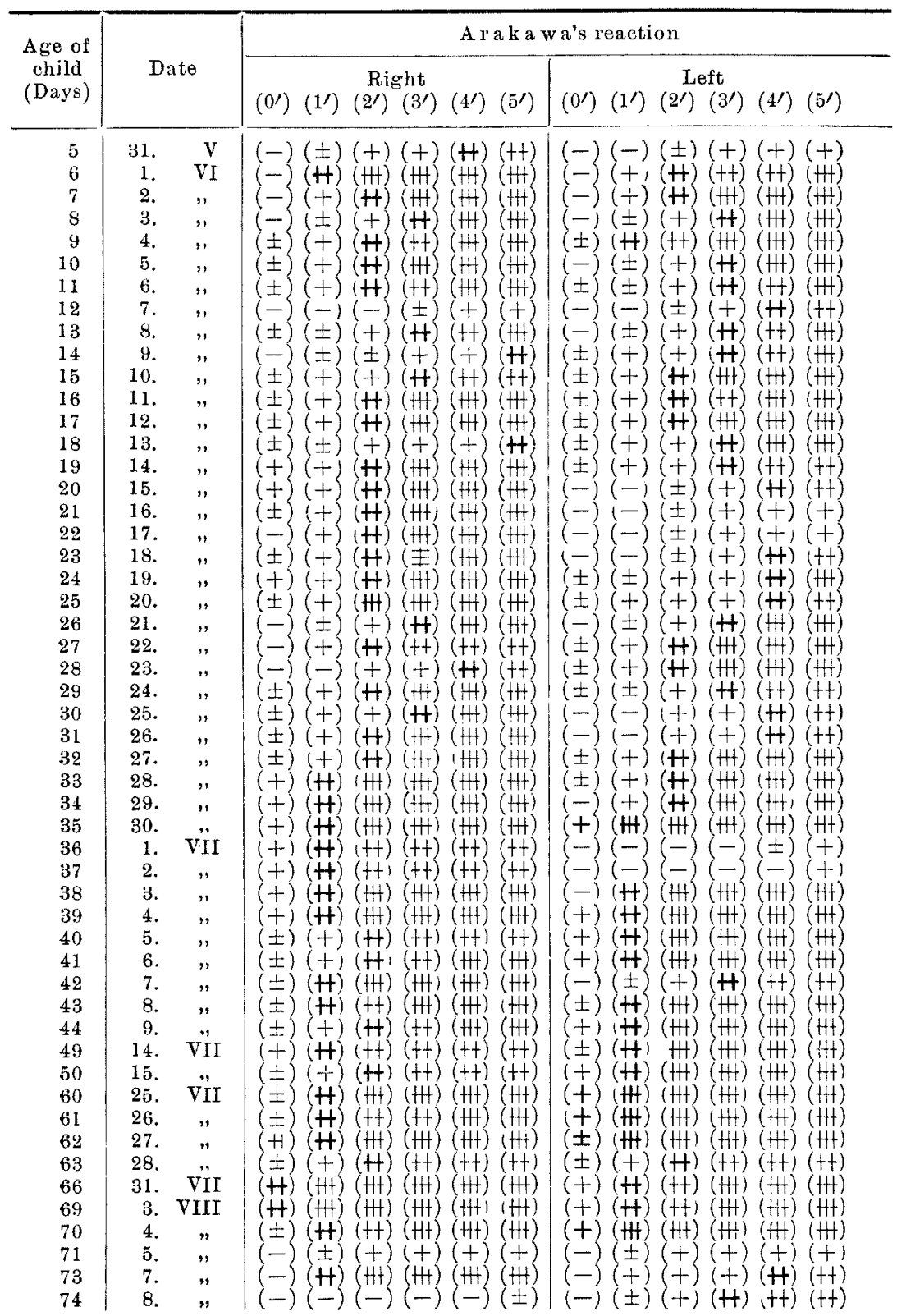




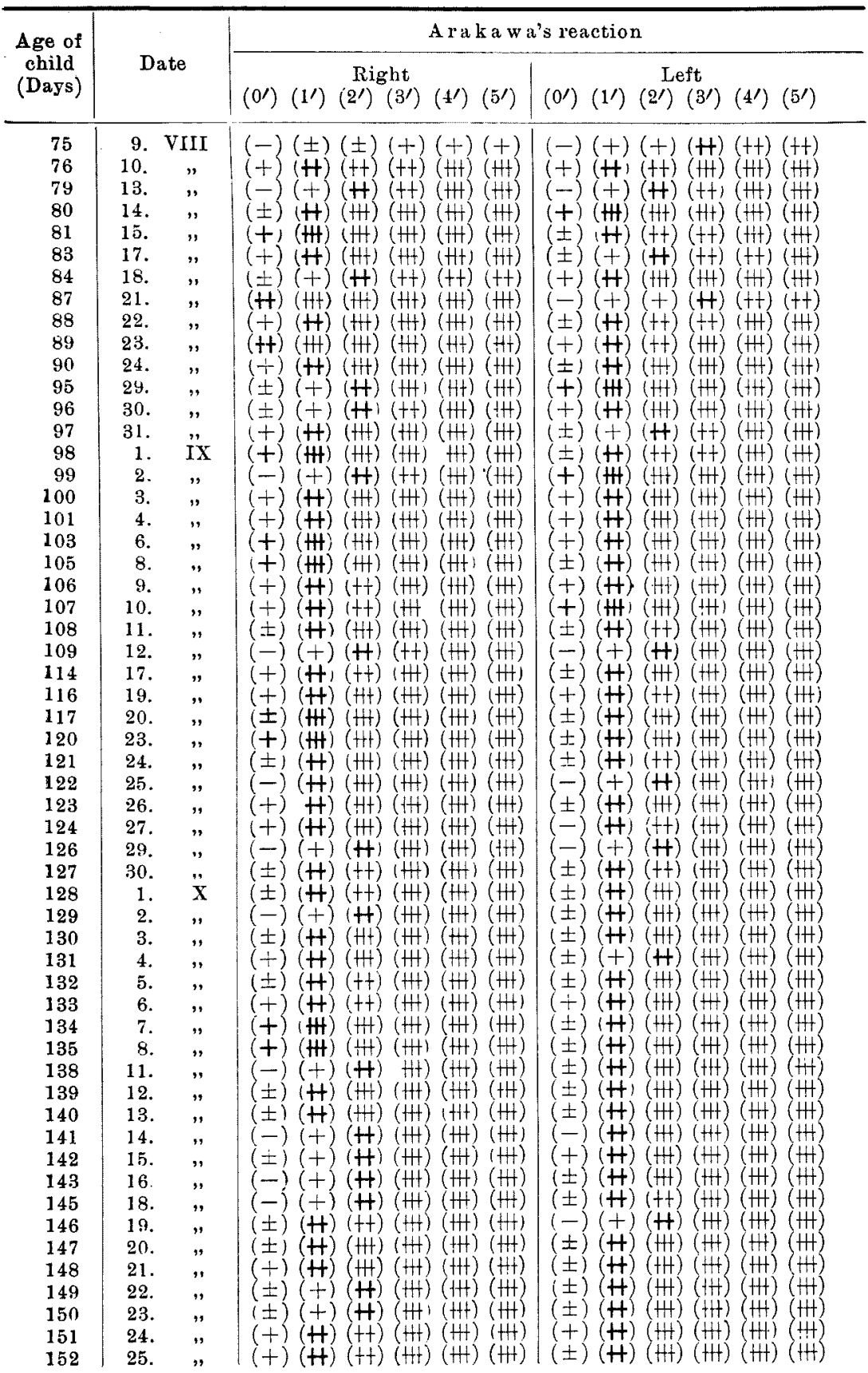




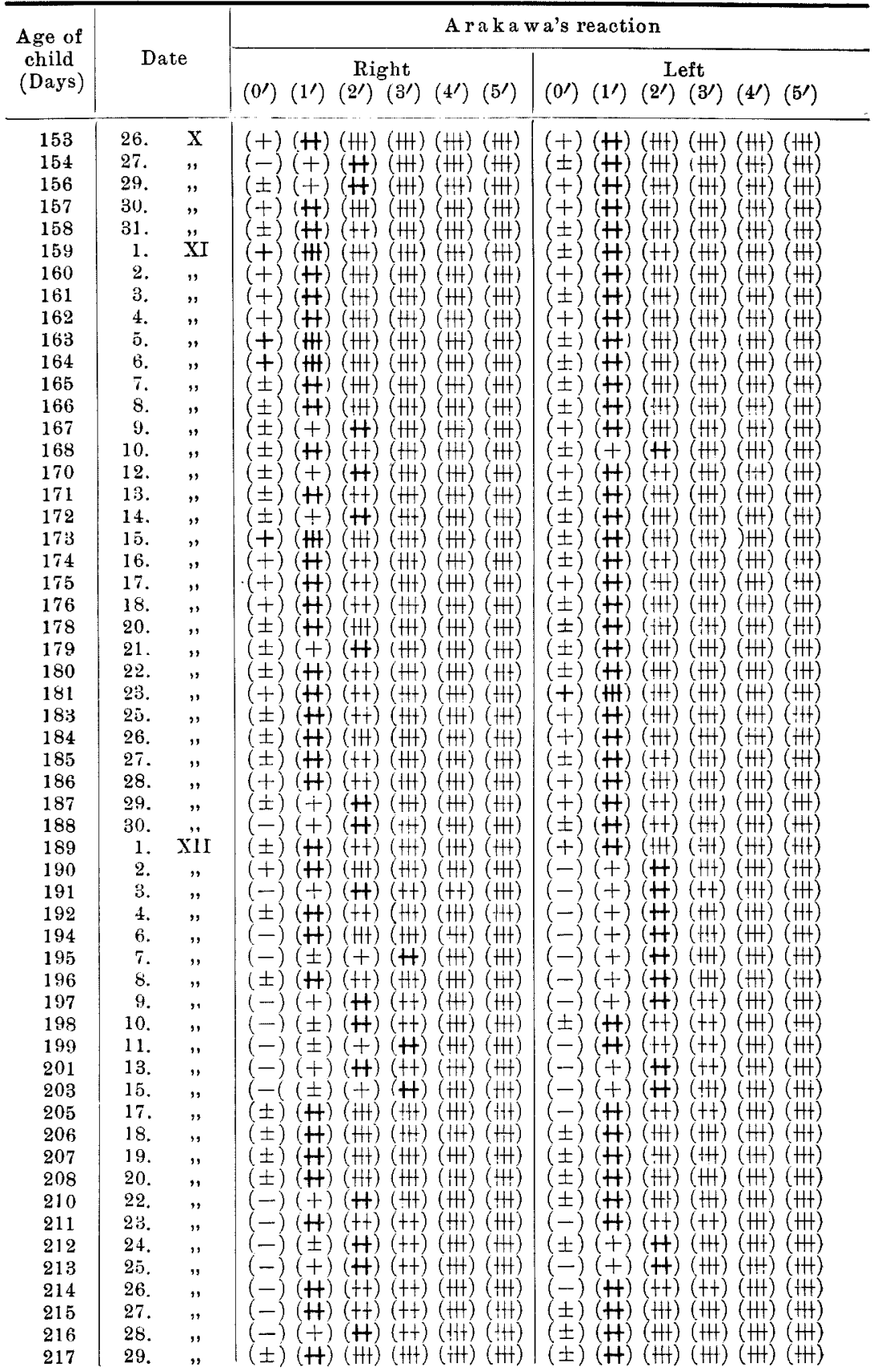




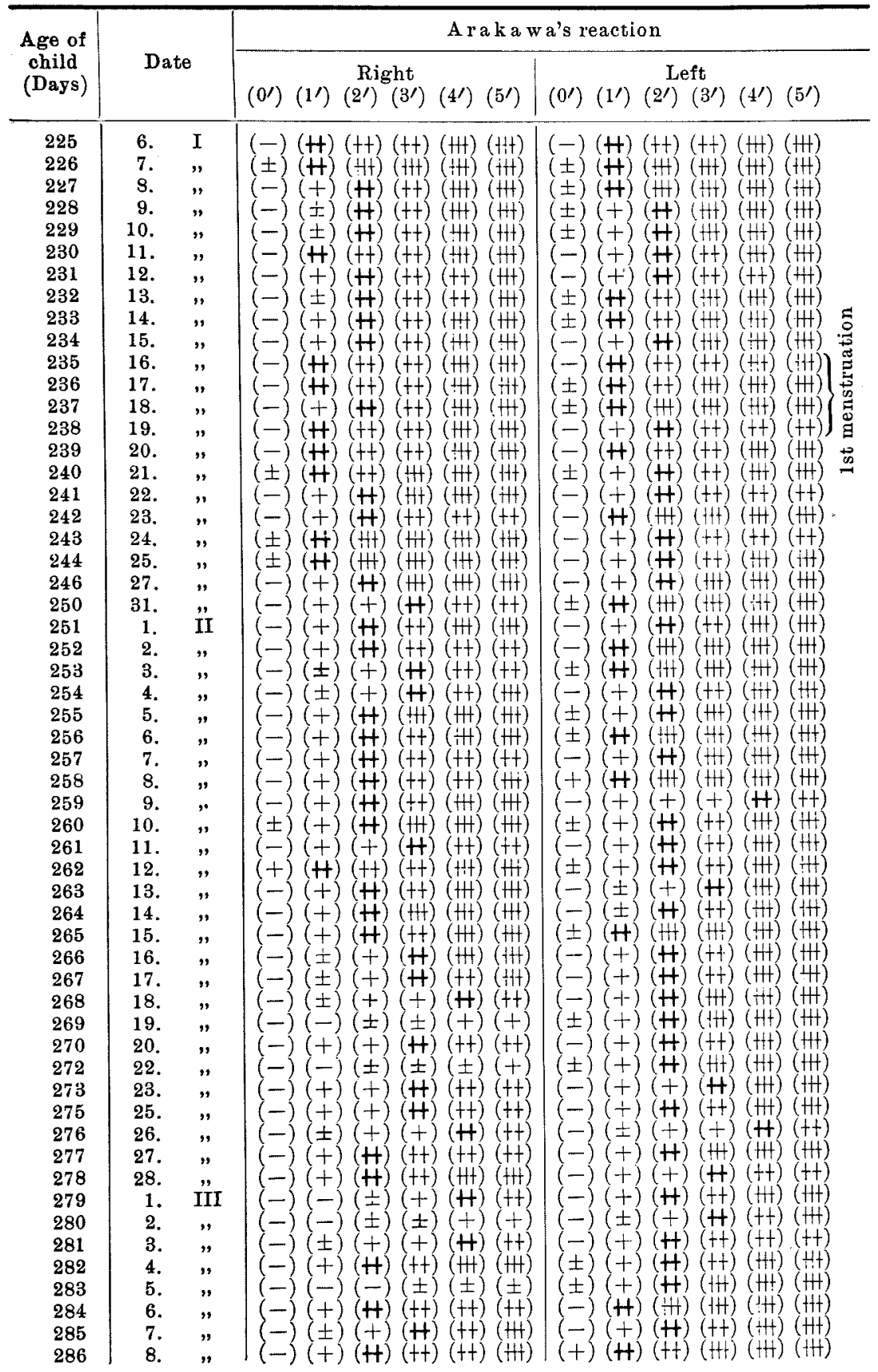




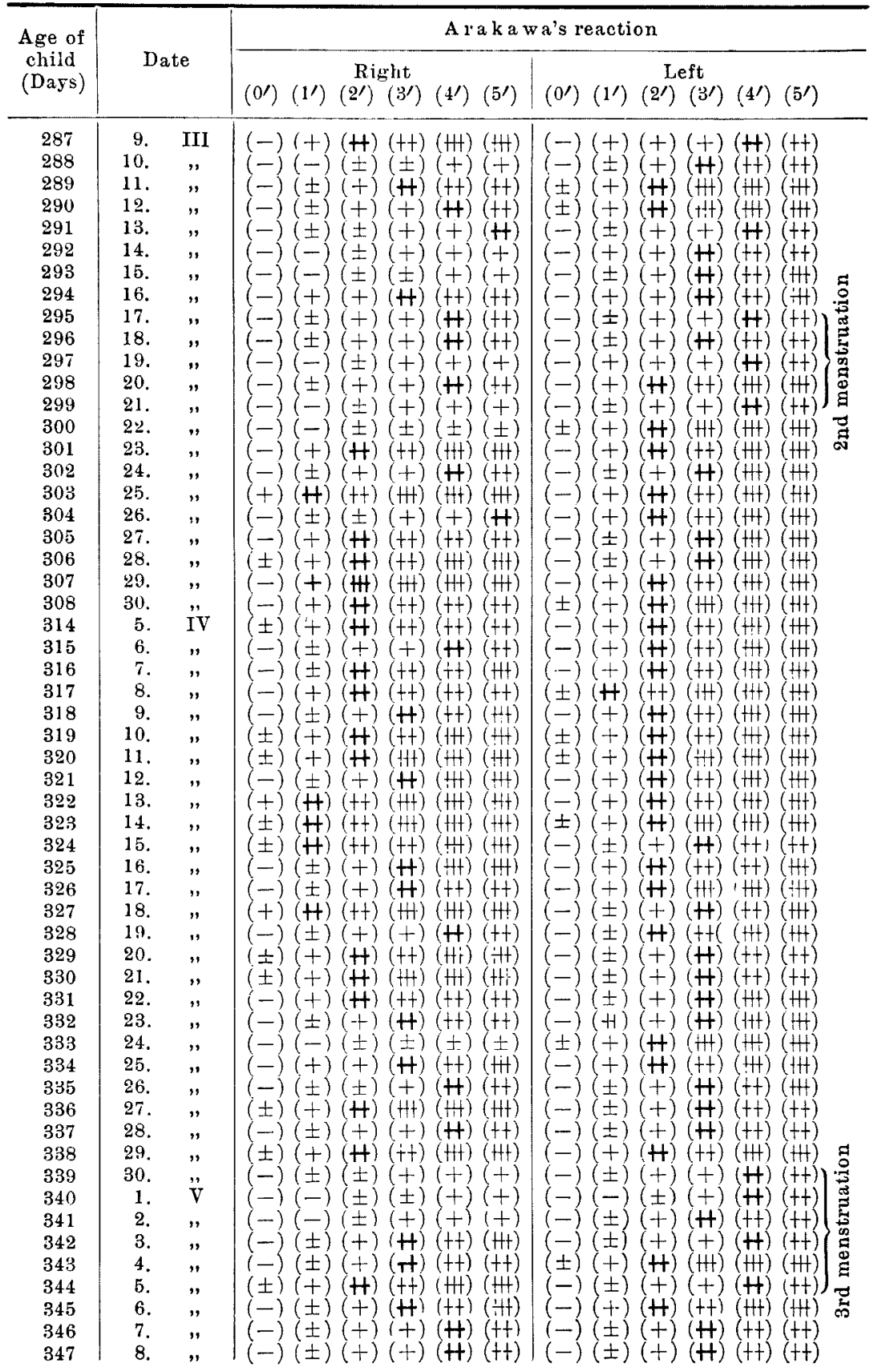




\begin{tabular}{|c|c|c|c|c|c|}
\hline \multirow{2}{*}{$\begin{array}{l}\text { Age of } \\
\text { child } \\
\text { (Days) }\end{array}$} & \multirow{2}{*}{\multicolumn{2}{|c|}{ Date }} & \multicolumn{3}{|c|}{ Arakawa's reaction } \\
\hline & & & $\begin{array}{c}\text { Right } \\
\left(0^{\prime}\right)\left(1^{\prime}\right)\left(2^{\prime}\right)\left(3^{\prime}\right)\end{array}$ & $\left(4^{\prime}\right)\left(5^{\prime}\right)$ & $\begin{array}{c}\text { Left } \\
\left(0^{\prime}\right)\left(1^{\prime}\right)\left(2^{\prime}\right)\left(3^{\prime}\right)\left(4^{\prime}\right)\left(5^{\prime}\right)\end{array}$ \\
\hline 348 & 9. & $\mathrm{~V}$ & $(-)( \pm)(+)(+$ & $(t+)(t+)$ & $(-)( \pm)( \pm)(+)(+)(t+)$ \\
\hline 349 & 10. & " & $(-)( \pm)( \pm) i+$ & $(+)(+)$ & $(-)( \pm)( \pm)$ \\
\hline 350 & $1 \mathrm{I}$ & $"$ & $(-)(-)( \pm)( \pm$ & $(+)(H)$ & $(-)(-)\} \pm$ \\
\hline 351 & & $"$ & $(-)( \pm)(+) i+$ & $(+)(+)$ & $(-)( \pm)(+)$ \\
\hline 352 & 13. & $"$ & $(-)(-)( \pm)( \pm$ & $( \pm)(+)$ & $(+)(+)$ \\
\hline 353 & 14. & ", & $(-)( \pm)( \pm)(+$ & $(+)(H)$ & $(-)(-)(-)( \pm)$ \\
\hline 354 & 15. & $"$ & $(-)(-)(-))( \pm$ & $(t)(t)$ & $(-)(-)(-)(-)( \pm)( \pm)$ \\
\hline 355 & 16. & ", & $(-)(-)( \pm)( \pm$ & $(+)(+)$ & $(-)-\{( \pm)( \pm)(+)(+)$ \\
\hline 356 & 17. & $"$ & $(-)( \pm)( \pm)(+$ & $(+)(H)$ & $(-)( \pm)(+)(+)(H)(+t)$ \\
\hline 357 & 18. & $"$ & $(-)(-)( \pm) i+$ & $(+)(+)$ & $(-)(-)(+)$ \\
\hline 358 & 19. & $"$ & $(-) i \pm j(+)(+$ & $(H)(t+)$ & $(-)( \pm)(+)(+)(+)(H)$ \\
\hline 359 & 20. & $"$ & $(-)( \pm)( \pm) i+$ & $(+)(+)$ & $(-)(-)(+)(+)(+)(+)$ \\
\hline 360 & & ", & $(-)(-)( \pm)( \pm$ & $(+)(+)$ & $(-)(-)(-)( \pm)(+)(+)$ \\
\hline 361 & 22. & $"$ & $(-)(-)( \pm) i \pm$ & $(+5 i+j$ & $(-(-)(-)( \pm)(+)(+)$ \\
\hline 362 & 23. & $"$ & $(-)(-)(-))( \pm$ & $( \pm)( \pm)$ & $(-)( \pm)(+)(+)(+)(H)$ \\
\hline 363 & 24. & $"$ & $(-)( \pm)( \pm)( \pm$ & $( \pm)(+)$ & $(-)( \pm)( \pm)( \pm)(+)(+)$ \\
\hline 864 & 25. & $"$ & $(-)(-)\}-\{)( \pm$ & $( \pm)( \pm)$ & $(-)( \pm)( \pm)(+)(+)(+)$ \\
\hline 365 & 26. & $"$ & $(-)(-)(-)(-$ & $(-)(-)$ & $(-)(-)(-)( \pm)( \pm)(+)$ \\
\hline 366 & 27. & $"$ & $(-)( \pm)( \pm)( \pm$ & $(+)(+)$ & $(-)(-)(+)(+)(+)(H)$ \\
\hline
\end{tabular}

on less different in reaction each day, very probably due to a slight general or local cause. However one can see, by glancing over Table II, and by paying special attention to the last part of the Table, that Arakawa's reaction in a healthy case is fairly constant every day. I shall observe the whole course by dividing it into 4 periods.

(a) Colostrum (1st-12th day) and Transition (12th-30th day).

The lactant, a primipara, secreted abundant milk, though a sufficient amount for Arakawa's reaction could not be collected during the first four days. From the 5th day the reaction was examined every day. Colostric and transitionary milks were slightly weaker in reaction, in comparison with milks in the later stage.

(b) Early Mature Period (1-4 months).

The reaction in this period was on most days strong in both breasts, even though a very weak reaction occurred in a few instances (36th and 37 th days, left and 74th day, right). Both breasts produced in general a good milk on most days.

(c) Middle Mature Period (4-9 months).

In this period A rakaw a's reaction was generally good, specially on the left side and fairly constant. And no very weak reaction occurred on either side during the whole period. But from the 8th month on, Arakawa's reaction began to fluctuate. The first menses took place in this period, of which I shall relate later. 
The infant remained healthy, though dentition began and a grippal fever continued for a few days, in the 7 th month.

(d) Late Milk (10-12 months).

The fluctuation of the Arakawa reaction was more remarkable in this period than in the last month of the previous period, though the weak reaction became stronger in the eleventh month. But later the reaction in general became weaker and weaker, so that during the whole twelfth month a strong reaction did not happen even on a single day. In a word, Arakawa's reaction was negative in the twelfth month. The 2 nd and $3 \mathrm{rd}$ menses occurred during this period, and about the time of the $3 \mathrm{rd}$ menses the infant suffered from infantile diarrhoea. Cow's milk was given to the sick infant instead of the Arakawanegative milk, so that the mother's milk became less and less abundant in amount. The absolute weaning took place on the 361st day after birth. Mother's milk obtained 10 days after the absolute weaning was yellow, like colostric milk and remained negative to Ar a k a wa's reaction as long as 15 minutes.

\section{Seasons and Arakawa's Reaction.}

The whole course was subject to different factors in different periods, but if we want to know the seasonal change of the whole course of A rakawa's reaction, we find that the reaction was good in summer and autumn. From our daily experience Arakawa's reaction seems to be strong especially in the summer, and so the fact that the milk in the mature period was good may partly have been due to the seasonal influence.

\section{Menses and Arakawa's Reaction.}

As to the relation between Arakawa's reaction and menses, Matsud $a^{93}$ states that the reaction will become weak or negative during the menses in $38.0 \%$ cases.

During the whole one year of my case, three menses occurred as stated above (Cf. Table II). The first, and possibly the 2nd menses, does not seem to have exerted a special influence on A rakawa's reaction, while the third menses did, I believe, have an effect on the reaction, especially because the infant suffered from infantile diarrhoea at this time. A substitution of cow's milk cured the disease. It would

9) F. Matsuda, Jika Zasshi, 1932, No. 371, 609. 
have been much more instructive, if the amount of methyl glyoxal-like substance in the milk had been determined in such instances. At any rate, it is probable that human milk can be poisonous at the time of the menses.

\section{Curve of Growth of Infant and Arak awa's Reaction.}

A number of factors should be taken to account, if the curve of growth is to be considered. But if only the relation between the Arakawa's reaction and the curve of growth is shown by way of a diagram, the steepest part of the curve of growth falls in the period in which Arakawa's reaction was strong and constant (Cf. Figure).

Fig. 1. Curve of growth of infant and constancy of Arakawa's reaction.

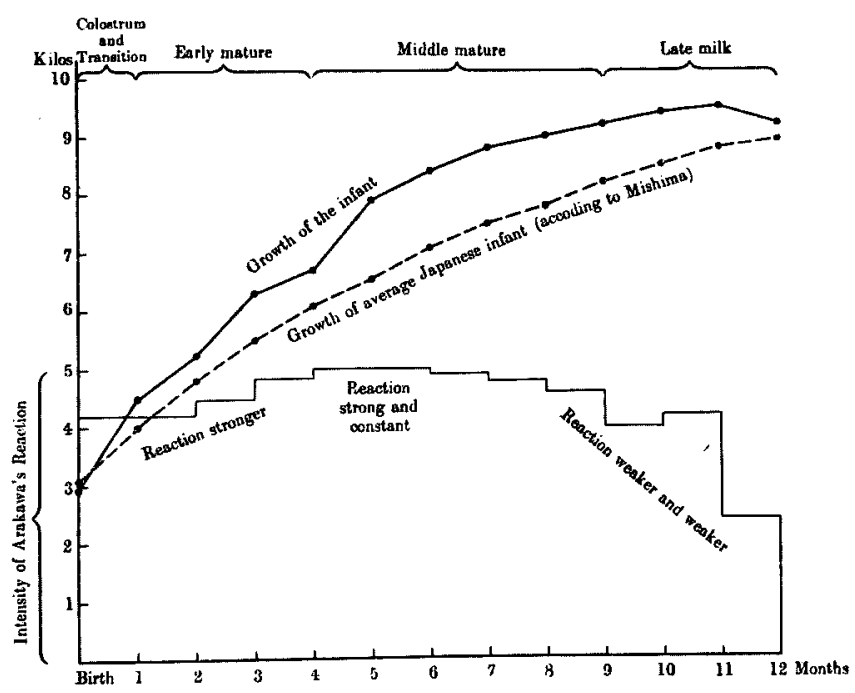

5. Vitamin B Administration and Arakawa's Reaction.

The relation between Arakawa's reaction and vitamin $B$ has been repeatedly shown (Cf. Arakawa, ${ }^{10)}$ Takamatsu, ${ }^{11}$ above all).

It was stated above that various factor's must have been exerting some influence or other on the whole course of the Arakaw a's reac-

10) T. Arakawa, Tohoku J. Exp. Med., 1930, 16, 109-122.

11) A. Takamatsu, Tohoka J. Exp. Med., 1934, 23, 46. 
tion of my cases. Besides the different factors above discussed, among others one thing very important is the supply of vitamin $B$.

The first administration of vitamin B in my case took place some time before the birth and continued as late as the 16th day after birth. 3 grms. of Beriberol powder was given per day. The second supply occurred on the 26th day and continued one week long: $3 \mathrm{grms}$. of Spelzon was given per day. The influence of the first administration of the vitamin does not seem to have been remarkable, but it is not difficult to suppose that it helped not to make Arakawa's reaction worse, because colostrum milk, according to our daily experience, is more prone to negative reaction. The second supply had a somewhat definite influence, as will be seen from Table II. But when vitamin $\mathrm{B}$ was administered for the third time, in the form of liquid Spelzon, it was unable to influence A rak a wa's reaction to any degree, though the amount used was 15-20 grms. per day and continued for about 10 days, to restore A rakaw a's reaction to normal in such a case, it must have been necessary to take such a measure as described in Takamatsu's ${ }^{12)}$ report; - a combined use of vitamin B and yakriton.

\section{REMARKS.}

A rakawa's reaction of a mother of a healthy baby was examined throughout nearly a whole year and the influences of various factors on the reaction were discussed. But the most important conclusion to be derived from such a long-timed observation is the constancy or reliability of Arakawa's reaction. If the result of only a few days, the reaction, for instance, 30. VI.-3. VII. (Table II) or of 5. VIII.-9. VII. (Table II), is seen, then it may appear as a rather capricious reaction, but if the result of a longer time, say from 30 . X to till $9 . \mathrm{XI}$, or from 16. XI till 38. XII, is seen, then the reaction is fairly constant or shows a somewhat regular propensity. As for various types of Ara$\mathrm{kawa}$ 's reaction of a short-timed period, Prof. Sato and Moriwaki will report in the near future.

\section{Conclusions.}

The most important conclusion to be derived from such a longtime observation is the constancy or reliability of Arakawa's reaction.

12) A. T aka matsu, Tohoku J. Exp. Med., 1934, 23, 372. 